\title{
Research on Construction Scheme and Characteristic Implementation Approach of Promotion Plan of "E- class" in Applied Undergraduate University
}

\author{
Xin Dong \\ Zhuhai College of Jilin University \\ Zhuhai, China 519041
}

\author{
Rui Guo \\ Zhuhai College of Jilin University \\ Zhuhai, China 519041
}

\begin{abstract}
Network moral education is an important part of the overall strategic deployment of Chinese Communist Party and China. "E-Class" provides teachers and students with onestop, multi-functional, extensible and highly integrated of online and offline services, which is one of the key points of moral education in colleges and universities. The effective implementation of promotion program of "E-Class" can make applied undergraduate university transform the parallel management of intersected, striped and discrete traditional moral education and traditional teaching and research to the highly integrated system management of related, systematic and centralized network moral education and teaching, research, management, life, work, entertainment based on network.
\end{abstract}

Keywords-"E-class"; network moral education; promotion; implement approach

\section{INTRODUCTION}

With the development and popularization of application of Internet, especially mobile Internet technology, network power, naval supremacy, as well as air supremacy gradually become one of the important interests of the country, which jointly determine the stable development and long-term stability of country. Naval supremacy and air supremacy reflects the political, economic and military comprehensive strength of a country, while network power is on behalf of the political, cultural and ideological comprehensive strength of a country. Therefore, the Internet has become the main position of moral education in colleges and universities cooperating with the country to fight for network power. In the information age, information is transmitted fast, ideological trends are easy to spread, value orientation is active, and ideas are diverse. It is extremely urgent for network moral education in applied undergraduate universities to work hard to catch up with the times and time

Fund program: innovative key project of moral education in colleges and universities of Guangdong in 2015: under the guidance of "the Chinese dream" moral education model of synergy of military and students" (project number: 2015DYZD029); Key project of innovative cultivating project in Zhuhai college of Jilin university (Humanities and Social Sciences Category): A Study on the Multi-dimensional Construction Plan and Characteristic Implementation Approach of Promotion Program of "EClass"-Taking Zhuhai University of Jilin University as an Example (project number: 2016XJCQZD16) can't wait it to blaze new trails, form characteristics and surpass itself.

"E-class" is a comprehensive network interactive community integrating ideological education, education and teaching, service for life, culture and entertainment. In 2007 , some colleges and universities in Shanghai began to build online E-class, and carry out the pilot work within a small area. In the second half of 2009, Shanghai Education Committee and Municipal Commission of Education entrusted Research Center of Development of Network Culture in Shanghai Education System, combining with new technologies and applications of network, to establish public welfare network culture project, of which the Chinese name is "Shanghai college students online." "E-class" mainly takes college teachers and students as using object, integrating BBS, SNS, blog, micro blogging, mobile applications and other new Internet applications. Currently, "E-Class" has covered 59 universities in Shanghai, and carries out cobuilding in hundreds of colleges and universities of several provinces. In 2014, Ministry of Education and the State Internet Information Office issued " promotion plan of 'EClass' and "to promote the action plan and implementation plan of the online leading project of the Chinese college students", deciding to construct "E-Class" in colleges and universities of each provinces in batches on a voluntary basis. "E-Class" is a comprehensive network interactive community integrating ideological education, education and teaching, service for life, culture and entertainment as well as a high-quality platform for teachers and students, providing one-stop, multi-functional, and highly integrated online and offline comprehensive services.

\section{ApPlication VAlue of Promotion Plan of "E-} CLASS" AND INSUFFICIENT RESEARCH AND PRACTICE

\section{A. Application Value}

First, we can explore how can moral education in colleges and universities fight for network power cooperating with our party and country from the perspective of implementing the overall strategic deployment of our party and country on safeguarding national rights and improving national comprehensive strength through the study on the promotion plan of "E-class". 
Second, we can discuss how to scientifically formulate construction programs and rationally design implementation approach aiming at the promotion plan of "E-Class" from the perspective of actively supporting the overall arrangement of promotion of constructing "E-class" of local education authorities.

Thirdly, we should also study the top-level design of system integration and comprehensive development of promotion of "E-Class" in applied undergraduate universities, network moral education innovation and new round of college information construction from the perspective of trying to explore the innovative development of applied undergraduate universities.

Fourth, according to the current situation of moral education, we need to give full play to the role of network new media, new means and new carriers, innovate the developing ideas of construction of colleges and universities, effectively mobilize the enthusiasm of teachers and students and plan the "moral education and information intelligence platform of big data" that is applicable, convertible, shareable, economic and unique in applied undergraduate universities based on "E-class".

\section{B. Insufficient Research and Practice}

Although research on network moral education at home and abroad has achieved much progress and development, with the rapid development of the Internet, especially mobile Internet, the current domestic and foreign research has gradually exposed some shortcomings. First, it lacks innovation and falls behind the pace of development of the information age. Second, it lacks practicality with more theory than action. Third, the unity is not enough, since it puts too much emphasis on diversity and ignores the consistency. Four, it lacks comprehensiveness without multidisciplinary research. Fifth, it lacks flexibility, and puts too much emphasis on normalization, which hinders innovation and efficiency. Six, it lacks systematic, which still remains in the development stage of focus or stick.

The problems in the practice of plan of "E-Class" are: school managers and teachers have serious shortcomings at the level of understanding; they attach insufficient attention "E-Class" in many respects, but only regard "E-Class" as the general processing place of class affairs, or ignore the advantages of "E-Class"; they take "high click rate" as the only goal of "E-Class" network education under the administrative pressure; student's network rights and interests have not been effectively protected. The deviation of cognition and the blind practice lead to the deviation of the education and academic value of "E-Class", resulting in a certain gap between the exertion of network education function of "E-Class" and the ideal state and effect. These are what the major colleges and universities should pay more attention to and foresee in advance in the implementation process of "E-Class" network moral education.

\section{OVERALl DESIGN OF THE PROMOTION PlAN OF "E- CLASS" IN APPLIED UNDERGRADUATE UNIVERSITIES}

Based on the promotion plan of "E-class", we can combine with the practice of applied undergraduate universities, to scientifically and rationally develop the suitable construction program and design implementation approach for applied undergraduate universities, and make top-level design, comprehensive analysis, multi-dimensional thinking, three-dimensional design, and all-round implementation.

First, we should make clear a task that is paying high attention to the arduous task faced by current network moral education in applied undergraduate universities, which is, fighting for network power cooperating with our party and country and contributing our own strength for support of the party's leadership and safeguarding national rights and interests.

Second, we should define two goals: one is firmly supporting the requirements of strengthening moral education in colleges and universities from local education authorities; second is actively participating in the local construction work of promotion of "E-Class" in colleges and universities to contribute our own effort for the construction of "strong ideological province" and "moral education province ".

Thirdly, we should adhere to the three directions, combining the practical situation and development direction of the applied undergraduate universities, and take building a big data basic information platform as the orientation, take serving decision-making, management, teachers and students, teaching, and research as the orientation, and take the comprehensive application facing life, work, research, and entertainment as the orientation.

Fourth, we can give play to four advantages, that is, the local advantages of applied undergraduate universities, firstclass university advantages, pioneering and innovative advantages and economic strength advantage. For example, the Marxist colleges, local cultural and economic research institutions, network centers, higher education research institutes, laboratory of related departments and rich teacher resources of applied undergraduate universities can play a role with the help of the advantages.

Fifth, we should pay attention to the five considerations. Construction plan and implementation approach of "E-Class" in applied undergraduate university needs to give consideration to the national interests and personal interests, people-oriented and school-oriented, moral education and "moral entertainment" (integrate moral education in entertainment, culture, Life, and work), independent innovation and co-construction and sharing, unified comprehensiveness and characteristic focus. 


\section{THE IMPLEMENTATION STEP OF PROMOTION PLAN OF "E-CLASS" IN APPLIED UNDERGRADUATE UNIVERSITIES}

\section{A. Construction of Network Information}

Based on completing the basic network infrastructure and network information construction under the traditional Internet environment, the applied universities should use the promotion plan of "E-Class" as the development opportunity, to scientifically plan and design the third phase of the network information construction work based on "Internet +", big data, and mobile Internet combing with the traditional Internet.

\section{B. Make Content Design of "E-Class" according to the Students' Undergraduate Study}

New students of applied undergraduate universities should register for the "E-Class" system before entering the school to get familiar with the school environment, professional content, teachers, classmates and campus life in advance; at the same time, for "E-Class", the comprehensive network social platform integrating education, service, communication and management, it is indispensable step to improve the network information technology, strengthen self-promotion, and attract students to improve the user's viscosity for the promotion and application of "E-Class" in colleges and universities. Since "E-Class" has the function of blog and community activities and so on, carrying out the activities that college students are interested in on the intelligent platform of "E-Class" can mobilize the enthusiasm of students to concern about the "E-Class" culture, so that students can also benefit from the activities. We can build business mentor platform on business relying on "E-Class", so graduates and majors with high requirements for technical skills can have access to social needs from "E-Class" network timely, learn, discuss and train related skills, and even get some real and reliable employment information. This valuable information is also the key factor that attracts the attention of college students to "E-Class".

\section{Continue to Improve the Quality and Form}

\section{Characteristics in Improving the Use Rate of "E-Class"}

The use rate of "E-Class" is gradually increasing, owing to the promotion of colleges and universities, the selfpublicity of products, the promotion of competitive activities and the promotion and application of student employment. "E-Class" entering the university is not a commercial activity but an organized public welfare platform that goes through the systematic planning. The improvement of the use rate of "E-Class" is inseparable from the administrative task of colleges and universities. Applied undergraduate universities should further study how to do the top design to avoid weaknesses, improve cost-efficiency, develop programs and innovate implementation scientifically, rationally, systematically and comprehensively proceeding from the reality and according to their own characteristics. At the same time, we should deeply study the platform features of "E-Class" and the way to find the greatest common divisor of E-Class and overall development of applied undergraduate universities to gradually expand and form characteristics on this basis.

\section{CONSTRUCtion OF THE PROTECTION MECHANiSM FOR THE PROMOTION PLAN OF "E-CLASS" IN APPLIED UNDERGRADUATE UNIVERSITY}

First, basing on the overall situation and strengthening leadership is the leading basis of successful promotion plan of "E-Class". The current promotion plan is one of the key points of moral education in colleges and universities, and network moral education is an important part of the overall strategic plan of the party and the country. How to seize the great fleeting opportunity for development needs the leading groups at all levels of applied undergraduate colleges to base on the overall situation, recognize the situation, to set up a strong leader group.

Second, unified thought and reaching a consensus are the ideological basis of successful promotion plan of "E-Class". Construction of "E-Class", network moral education and informatization and curriculum reform involve the major adjustments of the original system of applied undergraduate university and great changes in the system, which will certainly lead to changes in the overall pattern of colleges and universities. A slight move in one part may affect the situation as a whole. Only a high degree of unified thought and broad consensus can ensure the smooth progress of the overall work.

Third, the protection of funds and corresponding to reality are the material basis of stable development of promotion plan of "E-Class". On the one hand, construction of "E-Class" and informationization and curriculum reform need some capital investment to ensure the normal operation and sustainable development of the system and platform. On the other hand, it is necessary to base on the reality of applied undergraduate university, and advance in regular order, go ahead steadily and surely without rushing to fruition and seeking perfection, and strive for the construction fund support of education and research departments at all levels when increasing income and reducing expenditure to make up for inadequate research fund through actively supporting declaration of projects outside school.

Fourth, putting people first and strengthening the team is the fundamental impetus for continuous development of the promotion plan of "E-Class". On the one hand, construction of E-Class, informationization and curriculum reform should take into account the interests of most teachers and students of applied undergraduate universities. We should take personal interests, school interests, national interests into account, and only putting people first can promote the construction effectively. On the other hand, construction of E-class, informationization requires professional personnel and professional teams, so colleges and universities not only need to play their own talent advantages, but also should introduce, use and integrate external forces, and organize a construction team that combines arts and science, and inside and outside with rational composition. 


\section{CONCLUSION}

Internationally, the western countries have a common point in the implementation of ideological and political education in colleges: forming a radial comprehensive education network with cooperation of families, schools, and society centering on school. For our country, colleges and universities are the important bases that transport highquality talents with both political integrity and ability for the society. When applied undergraduate universities deeply study the construction plan and implementation approach of promotion of "E-Class" suitable for the actual situation and development characteristics of the schools, they can combine improving the social responsibility of college students and the sense of mission of realizing the great rejuvenation of "China Dream", combine the education, guidance of healthy development of individual students and social development and realize the promotion of applied undergraduate universities from first-class to excellence by taking the construction of "E-Class" as development opportunity.

\section{REFERENCES}

[1] Chen Huadong. "E-Class": A New Exploration of Network Ideological and Political Education in Web2.0. Ideological \& Theoretical Education, 2011 (07)

[2] Shen Man, Xi Wenfang. Research on Work Strategy of Improving the Stickiness of General Users Ideological \& Theoretical Education, 2014 (8)

[3] Feng Yongtai, Wang Zhao, Chen Xi. The benign interaction between "E-Class"and teaching in colleges and universities China University Teaching, 2014(5): 67-69

[4] Yang Xiao. Management of "Easy Class" in Colleges and Universities - Taking some colleges in Shanghai as Examples Shanghai Normal University, 2013(3)

[5] Wu Hao, Huang Yuxin. Thinking and Practice of Building Big Data Platform of Network Ideological and Political Education in Colleges and Universities Based on "E-Class" - Taking Chongqing University as an Example Studies in Ideological Education, 2016(1)

[6] Bian Qian. An Analysis and the Countermeasures Study of the Current Using Situation of "E-Class" by College Students Journal of Jiamusi Vocational Institute, 2017(2) 